\title{
Preliminaries to a Psychological Model of Musical Groove
}

\author{
Olivier Senn*, Dawn Rose, Toni Bechtold, Lorenz Kilchenmann, Florian Hoesl, \\ Rafael Jerjen, Antonio Baldassarre and Elena Alessandri
}

School of Music, Lucerne University of Applied Sciences and Arts, Lucerne, Switzerland

Keywords: music, groove, entrainment, dancing, pleasure, body movement, sensorimotor synchronization

\section{INTRODUCTION}

Humans often feel motivated to move their bodies in response to music; this experience is generally referred to as "feeling the groove." In this paper we discuss ideas about how the experience of groove can be modeled from a psychological point of view.

As a musical term, groove was originally coined in the context of Western popular music

OPEN ACCESS

Edited by:

Rosie Perkins,

Royal College of Music

United Kingdom

Reviewed by:

Alex Hofmann,

University of Music and Performing

Arts Vienna, Austria

Maarten Grachten,

Austrian Research Institute for

Artificial Intelligence, Austria

*Correspondence:

Olivier Senn

olivier.senn@hs/u.ch

Specialty section

This article was submitted to

Performance Science,

a section of the journal

Frontiers in Psychology

Received: 21 February 2019

Accepted: 09 May 2019

Published: 04 June 2019

Citation:

Senn O, Rose D, Bechtold T,

Kilchenmann L, Hoesl F, Jerjen R,

Baldassarre A and Alessandri E (2019)

Preliminaries to a Psychological Model

of Musical Groove.

Front. Psychol. 10:1228

doi: 10.3389/fpsyg.2019.01228
(Pfleiderer, 2006, p. 297ff; Abel, 2014, p. 18) where it has several meanings. It may refer to a repeated pattern that represents the basis of a piece ("a groove," Zbikowski, 2004). It may also denote the temporal interaction and effortless synchronized performance within a band ("to groove," Berliner, 1994, p. 388; Keil, 1995; Doffman, 2008, p. 11; Hosken, 2018), or the power of music to provoke body movement in listeners (Roholt, 2014, p. 85).

Music psychology builds on the last of these meanings and defines groove as a person's urge to move in response to music, accompanied by a feeling of pleasure (Madison, 2001, 2006; Janata et al., 2012). The psychological concept of groove is not restricted to Western popular music. It can be applied to any situation in which music triggers body movement, regardless of style or cultural background (Pressing, 2002). Since music is used for dancing in a majority of cultures (Kaeppler, 2000; Nettl, 2000), it is not surprising that there are concepts similar to groove in several languages, for example "balanço" in Brazilian (Vurkaç, 2012), "nori” in Japanese (Kawase and Eguchi, 2010), or "lüpfig” in Swiss German (Ringli, 2006, p. 123).

Empirical studies of groove have focused on musical properties that may have an effect on the groove experience. Some studies have investigated qualities that add interest to the music, such as syncopation (Sioros et al., 2014; Witek et al., 2014), rhythmic variability (Wesolowski and Hofmann, 2016), microtiming (Davies et al., 2013; Frühauf et al., 2013; Senn et al., 2016; Hofmann et al., 2017), or the interaction of rhythmic and harmonic complexity (Matthews et al., 2019). Other studies focused on properties that emphasize the regularity of the meter, such as beat salience (Madison et al., 2011) or tempo (Etani et al., 2018). Listeners' personal background (e.g., musical taste or familiarity with the repertoire) has also been found to influence the groove experience (Janata et al., 2012; Senn et al., 2018, 2019).

Since musical features, styles, surveyed populations, methods, and results differ greatly across empirical groove studies, it is a challenge to obtain a bigger picture of the progress made in the field. Therefore, this paper presents a psychological model of groove as a broad theoretical framework. This will enable the application of findings from groove studies to be considered from a wider perspective. Our model adopts Merker's (2014) idea that a person who experiences groove needs to have an inner representation of the music's temporal regularities, which allows for motor planning and synchronized body movement. The model also integrates Senn et al.'s (2018, p. 4) suggestion that music, in order to groove, must provide the listener with a motivation to move. 


\section{DESCRIPTION OF THE PROPOSED PSYCHOLOGICAL GROOVE MODEL}

Figure 1 presents a diagram of the hypothetical groove model. The central dashed box addresses the mental processes that are considered to be relevant to groove. These processes are triggered by the properties of the music (left), and they may lead to entrained body movement in the listener (right). The mental processes are influenced by the concrete listening situation (top) and the personal background of the listener (bottom).

\section{How Music Makes Us Want to Move}

Musical properties (Figure 1, left) is an umbrella term for all possible ways of describing music. The descriptors may be purely acoustic (e.g., loudness, frequency spectrum). They may refer to specific sound patterns resulting from the process of music making (e.g., clave rhythm, guitar riff, tabla taal, bass line) or to more abstract concepts that describe the development of music in time (e.g., meter, rhythm, syncopation, riff, harmony, form). The music may come from any style or cultural background. Since musical properties change considerably across contexts, the model is agnostic with respect to predefining a selection of musical properties that are relevant to groove.

As music is perceived by a listener, it triggers three mental processes (Figure 1, dashed box) that we hypothesize to be instrumental in causing an urge to move:

- Listeners derive an inner representation of temporal regularity from the music (Large and Jones, 1999; Vuust et al., 2018). The regularity may be based on an isochronous pulse or tactus as in many Western popular music styles (Merker et al., 2009). Yet, an isochronous pulse is by no means the only way to create a stable (and thus predictable) temporal structure, as Polak et al. (2016) have shown with respect to Malian jembe drumming. Empirical groove studies have confirmed that temporally regular musical properties predict groove, such as the salience of the beat (Madison et al., 2011) or the tempo (Etani et al., 2018). The neural representation of temporal regularity has received considerable attention in neuroscience (for an overview, see Ivry and Spencer, 2004; Paton and Buonomano, 2018).

- The temporal organization of the music may raise listeners' interest, which represents one dimension of the aesthetic response to art (Cupchik and Gebotys, 1990). Time-related interest may for example be rooted in rhythmic complexity: syncopation (Sioros et al., 2014; Witek et al., 2014), event density (Madison et al., 2011), or the interaction of rhythmic and harmonic complexity (Matthews et al., 2019) make the time organization of the music more interesting, and they have been found to affect the groove experience.

- Listening to music causes people to experience pleasure, which is another core dimension of the aesthetic response (Cupchik and Gebotys, 1990). Listening to music can be a hedonic activity that is considered to be rewarding and pleasurable by itself (Berlyne, 1974, p. 8; Zatorre and
Salimpoor, 2013). The role of pleasure in groove is not clearcut: pleasure has been used to define groove in some cases (Madison, 2001; Janata et al., 2012; Witek et al., 2014; Senn et al., 2018). Yet, recently, Matthews et al. (2019) treated pleasure as a mediator for groove.

It is the primary goal of groove research to investigate the urge to move in response to the music and the circumstances under which it arises. We hypothesize that listeners' representation of temporal regularity, their rhythm-related interest and the pleasure they experience while listening are causally linked to the urge to move. Specifically, our hypotheses are:

- $\mathrm{H}_{1}$ : The inner representation of temporal regularities in the music is a precondition for listeners' urge to move in response to the music.

- $\mathrm{H}_{2}$ : Interest in the temporal organization of the music increases listeners' urge to move.

$-\mathrm{H}_{3}$ : Listeners' pleasure while listening to the music also increases their urge to move.

- $\mathrm{H}_{4}$ : Musical properties do not affect the urge to move directly, but they are mediated through the representation of temporal regularity, rhythm-related interest and listening pleasure.

\section{How Body Movement Affects Our Perception of Music}

As a response to the urge to move, listeners' motor planning abilities may be activated (Zatorre et al., 2007; Wong et al., 2015) and map entrained body movement behavior onto the music. This process can be either conscious or subconscious (Phillips-Silver and Keller, 2012), and it can express itself as dancing, finger tapping or any other form of entrained movement (Clayton, 2012; Repp and Su, 2013; Burger et al., 2014; Ross et al., 2016).

We assume that entrained body movement activates two feedback loops:

- Sensory feedback loop: Expressing rhythmic processes through body movement can be understood as an instance of embodied perception (Wilson, 2002; Sebanz and Knoblich, 2010). As the person moves along with the music, the temporal regularities of the music are represented in various sensory systems in addition to hearing, such as touch (tapping, stomping, dancing), the vestibular system, and vision (head bobbing, dancing). Multimodal perception supposedly enhances the inner representation of temporal regularities (Spence and Driver, 2004). This in turn strengthens the urge to move and feeds back through motor planning to entrained body movement.

- Hedonic feedback loop: Entrained body movement is known to be a pleasurable activity by itself (Shaulov and Lufi, 2009). Moving in response to music has been found to increase the pleasure experienced by the listener (Bernardi et al., 2017). This closes a second feedback loop through pleasure, the urge to move, and motor planning back to movement. The hedonic feedback loop assumedly increases the individuals' endurance when repetitive movement tasks are synchronized with music, for example in sports (Karageorghis and Priest, 2012). 


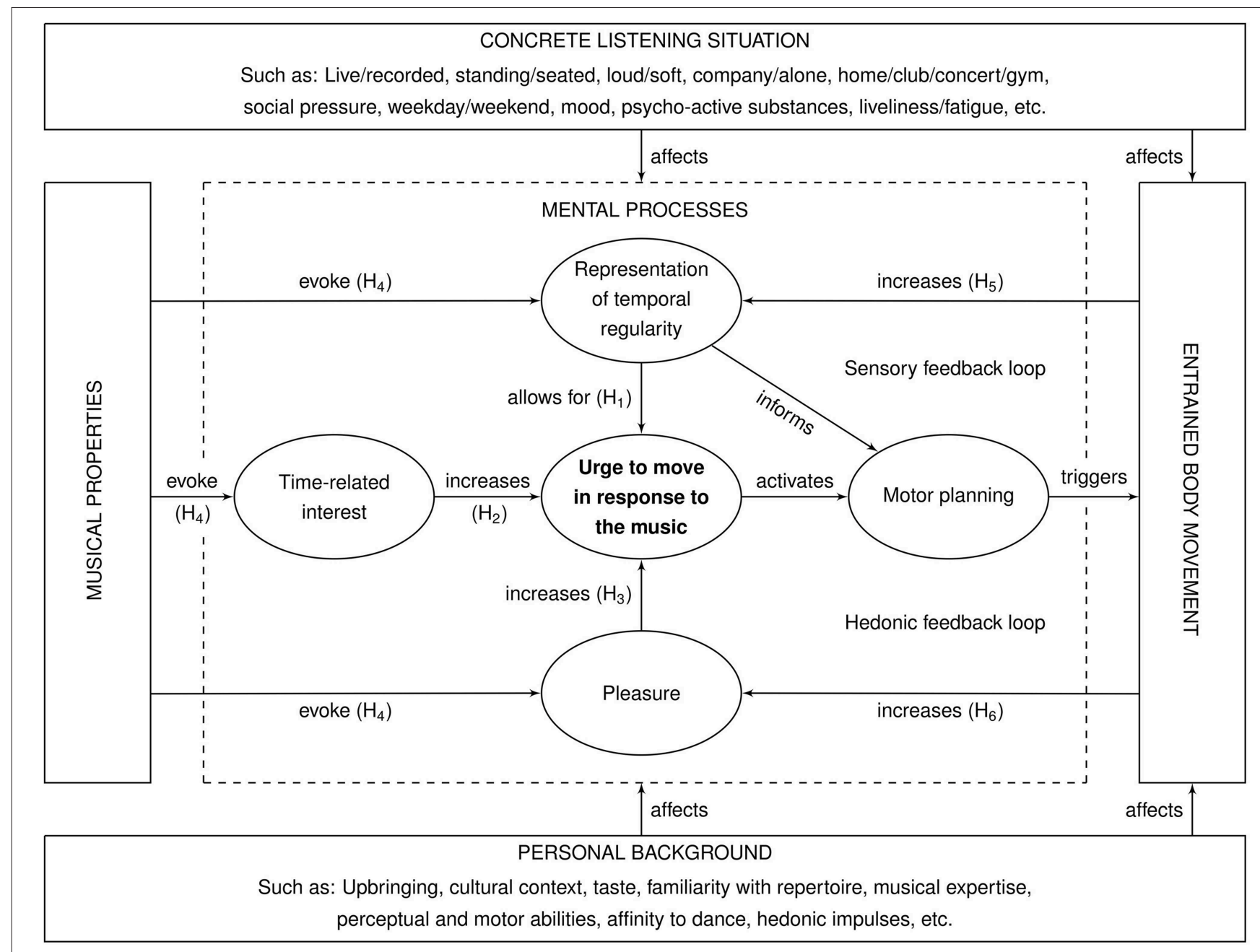

FIGURE 1 | Psychological groove model with hypothesized effects $\left(\mathrm{H}_{1}-\mathrm{H}_{6}\right)$.

Based on these assumptions, we formulate the following hypotheses:

$-\mathrm{H}_{5}$ : Entrained body movement strengthens the inner representation of the temporal regularity in the music.

- $\mathrm{H}_{6}$ : Entrained body movement increases the pleasure of listening to the music.

Musicians' entrained body movement directly affects the musical properties through the physical act of performance (thus linking the right- and leftmost boxes of Figure 1).

\section{How Contextual and Personal Factors Influence the Groove Experience}

A series of personal and contextual aspects have an influence on the described processes whenever a person hears music. Listeners' personal backgrounds (Figure 1, bottom) affect their responses to music (Levinson, 1987; Thompson, 2007). For example, it may be difficult for listeners to parse the temporal regularities if they are unfamiliar with the music (LaBarba et al., 1992) or if the rhythm is complicated. The interest and the experienced pleasure may be strong if the music agrees with listeners' musical taste or triggers positive biographic memory (Holbrook and Schindler, 1989). A person might have a general affinity to dancing or body movement, whereas another person might be more averse to these activities (Clegg et al., 2018). Amusia and beat deafness might impede decoding and representing the regularities of the music (Dalla Bella and Peretz, 2003; Sowinski and Dalla Bella, 2013), or health issues might prevent a person from carrying out entrained body movement (Thaut and Hoemberg, 2014).

The context of the concrete listening situation should also be taken into consideration (Figure 1, top). For example, live performances of rock music have been found to trigger a stronger groove experience than recorded performances (Swarbrick et al., 2019). Todd and Cody (2000) suggested that music triggers a stronger reaction in the listener when it is loud as opposed to soft. In some contexts, it might be socially desirable to express an urge to move through entrained body movement, while it might be inappropriate in others (e.g., dance event vs. classical music concert). A person might be in the right mood (Hunter 
et al., 2011) or too tired to react to the music. We can expect a person's emotional state (Juslin and Västfjäll, 2008; Koelsch, 2014) to influence the groove experience as well. Finally, the use of psycho-active substances such as alcohol or ecstasy may lower inhibitions that would otherwise prevent a person from moving with the music (Steele and Southwick, 1985; Milroy, 1999).

Personal and contextual factors affect the groove experience in a wide variety of ways. Several of these effects have been reported in previous research, but many have not yet been thoroughly investigated. Given the diversity of these effects and their potentially complex interactions, we refrain from formulating concrete hypotheses at this stage.

\section{CONCLUSIONS}

This opinion paper proposes a psychological model of musical groove. It postulates that musical properties affect listeners' urge to move, mediated by their inner representation of temporal regularity, by their timerelated interest, and by the pleasure they experience while listening. The listening context and the listener's own musical and personal background influence this process.

\section{REFERENCES}

Abel, M. (2014). Groove: An Aesthetic of Measured Time. Leiden: Koninklijke Brill. Berliner, P. F. (1994). Thinking in Jazz: The Infinite Art of Improvisation. Chicago IL: University of Chicago Press. doi: 10.7208/chicago/9780226044521.001.0001 Berlyne, D. E. (1974). Studies in the New Experimental Aesthetics: Steps Toward an Objective Psychology of Aesthetic Appreciation. Oxford: Hemisphere.

Bernardi, N. F., Bellemare-Pepin, A., and Peretz, I. (2017). Enhancement of pleasure during spontaneous dance. Front. Hum. Neurosci. 11:572. doi: $10.3389 /$ fnhum.2017.00572

Burger, B., Thompson, M. R., Luck, G., Saarikallio, S. H., and Toiviainen, P. (2014). Hunting for the beat in the body: on period and phase locking in musicinduced movement. Front. Hum. Neurosci. 8:903. doi: 10.3389/fnhum.2014. 00903

Clayton, M. (2012). What is entrainment? Definition and applications in musical research. Empir. Musicol. Rev. 7, 49-56. doi: 10.18061/1811/52979

Clegg, H., Owton, H., and Allen-Collinson, J. (2018). Challenging conceptions of gender: UK dance teachers' perceptions of boys and girls in the ballet studio. Res. Dance Educ. 19, 128-139. doi: 10.1080/14647893.2017.1391194

Cupchik, G. C., and Gebotys, R. J. (1990). Interest and pleasure as dimensions of aesthetic response. Empir. Stud. Arts 8, 1-14. doi: 10.2190/L789-TPPY-BD2Q-T7TW

Dalla Bella, S., and Peretz, I. (2003). Congenital amusia interferes with the ability to synchronize with music. Ann. N. Y. Acad. Sci. 999, 166-169. doi: 10.1196/annals.1284.021

Davies, M., Madison, G., Silva, P., and Gouyon, F. (2013). The effect of microtiming deviations on the perception of groove in short rhythms. Music Percept. 30, 497-510. doi: 10.1525/mp.2013.30.5.497

Doffman, M. R. (2008). Feeling the Groove: Shared Time and Its Meanings for Three Jazz Trios (Ph.D. Thesis). The Open University, Milton Keynes.

Etani, T., Marui, A., Kawase, S., and Keller, P. (2018). Optimal tempo for groove: Its relation to directions of body movement and Japanese nori. Front. Psychol. 9:462. doi: 10.3389/fpsyg.2018.00462

Frühauf, J., Kopiez, R., and Platz, F. (2013). Music on the timing grid: the influence of microtiming on the perceived groove quality of a simple drum pattern performance. Music. Sci. 17, 246-260. doi: 10.1177/1029864913486793

Hofmann, A., Wesolowski, B. C., and Goebl, W. (2017). The tight-interlocked rhythm section: production and perception of
The urge to move may lead to entrained body movement, triggering a nuanced interplay of sensory processes and hedonic states.

Empirical work and further theoretical discussion will be required to establish whether and to what extent this paper's hypotheses hold under scrutiny. Important elements may be missing in the current model, or existing elements might prove to be irrelevant. The mental processes described in the model are purely conceptual; future work will show how they relate to processes in the neural substrate.

\section{AUTHOR CONTRIBUTIONS}

OS drafted the manuscript and created the figure. DR, TB, LK, $\mathrm{FH}, \mathrm{RJ}, \mathrm{AB}$, and EA contributed to the development of the model and commented on the paper.

\section{FUNDING}

This research was supported by Schweizerischer Nationalfonds zur Förderung der wissenschaftlichen Forschung (www.snf.ch), grant number 100016162504 to OS. synchronisation in jazz trio performance. J. N. Music Res. 46, 329-341. doi: 10.1080/09298215.2017.1355394

Holbrook, M. B., and Schindler, R. M. (1989). Some exploratory findings on the development of musical tastes. J. Consum. Res. 16, 119-124. doi: $10.1086 / 209200$

Hosken, F. (2018). The subjective, human experience of groove: a phenomenological investigation. Psychol. Music 46, 1-17. doi: 10.1177/0305735618792440

Hunter, P. G., Schellenberg, E. G., and Griffith, A. T. (2011). Misery loves company: mood-congruent emotional responding to music. Emotion 11, 1068-1072. doi: $10.1037 / \mathrm{a} 0023749$

Ivry, R. B., and Spencer, R. M. (2004). The neural representation of time. Curr. Opin. Neurobiol. 14, 225-232. doi: 10.1016/j.conb.2004.03.013

Janata, P., Tomic, S. T., and Haberman, J. M. (2012). Sensorimotor coupling in music and the psychology of the groove. J. Exp. Psychol. Gen. 141, 54-75. doi: $10.1037 / \mathrm{a} 0024208$

Juslin, P. N., and Västfjäll, D. (2008). Emotional responses to music: the need to consider underlying mechanisms. Behav. Brain Sci. 31, 559-575. doi: 10.1017/S0140525X08005293

Kaeppler, A. L. (2000). Dance ethnology and the anthropology of dance. Dance Res. J. 32, 116-125. doi: 10.2307/1478285

Karageorghis, C. I., and Priest, D.-L. (2012). Music in the exercise domain: a review and synthesis (Part II). Int. Rev. Sport Exerc. Psychol. 5, 67-84. doi: 10.1080/1750984X.2011.631027

Kawase, S., and Eguchi, K. (2010). The concepts and acoustical characteristics of 'Groove' in Japan. PopScriptum 11, 1-45.

Keil, C. (1995). The theory of participatory discrepancies: a progress report. Ethnomusicology 39, 1-19. doi: 10.2307/852198

Koelsch, S. (2014). Brain correlates of music-evoked emotions. Nat. Rev. Neurosci. 15, 170-180. doi: 10.1038/nrn3666

LaBarba, R. C., Kingsberg, S. A., and Martin, P. K. (1992). Cerebral lateralization of unfamiliar music perception in nonmusicians. Psychomusicology 11, 119-124. doi: 10.1037/h0094127

Large, E. W., and Jones, M. R. (1999). The dynamics of attending: how people track time-varying events. Psychol. Rev. 106, 119-159. doi: 10.1037/0033-295X.106.1.119

Levinson, J. (1987). Music, Art, and Metaphysics. Oxford, NY: Oxford University Press. 
Madison, G. (2001). "Different kinds of groove in jazz and dance music as indicated by listeners' ratings," in Proceedings of the VII International Symposium on Systematic and Comparative Musicology III International Conference on Cognitive Musicology (Jyväskylä: Department of Musicology, University of Jyväskylä), 108-112.

Madison, G. (2006). Experiencing groove induced by music: consistency and phenomenology. Music Percept. 24, 201-208. doi: 10.1525/mp.2006.24.2.201

Madison, G., Gouyon, F., Ullén, F., and Hörnström, K. (2011). Modeling the tendency for music to induce movement in humans: first correlations with low-level audio descriptors across music genres. J. Exp. Psychol. 37, 1578-1594. doi: $10.1037 / \mathrm{a} 0024323$

Matthews, T. E., Witek, M. A. G., Heggli, O. A., Penhune, V. B., and Vuust, P. (2019). The sensation of groove is affected by the interaction of rhythmic and harmonic complexity. PLoS ONE 14:e0204539. doi: 10.1371/journal.pone.0204539

Merker, B. (2014). Groove or swing as distributed rhythmic consonance: introducing the groove matrix. Front. Hum Neurosci. 8:454. doi: $10.3389 /$ fnhum.2014.00454

Merker, B. H., Madison, G. S., and Eckerdal, P. (2009). On the role and origin of isochrony in human rhythmic entrainment. Cortex 45, 4-17. doi: 10.1016/j.cortex.2008.06.011

Milroy, C. M. (1999). Ten years of "ecstasy". J. R. Soc. Med. 92, 68-71. doi: $10.1177 / 014107689909200206$

Nettl, B. (2000). "An ethnomusicologist contemplates universals in musical sound and musical culture," in The origins of music, eds N. L. Wallin, B. Merker, and S. Brown (Cambridge MA: MIT Press), 463-472.

Paton, J. J., and Buonomano, D. V. (2018). The neural basis of timing: distributed mechanisms for diverse functions. Neuron 98, 687-705. doi: 10.1016/j.neuron.2018.03.045

Pfleiderer, M. (2006). Rhythmus: Psychologische, theoretische und stilanalytische Aspekte populärer Musik. Bielefeld: Transcript Verlag. doi: 10.14361/9783839405154

Phillips-Silver, J., and Keller, P. (2012). Searching for roots of entrainment and joint action in early musical interactions. Front. Hum. Neurosci. 6:26. doi: 10.3389 /fnhum.2012.00026

Polak, R., London, J., and Jacoby, N. (2016). Both isochronous and nonisochronous metrical subdivision afford precise and stable ensemble entrainment: a corpus study of malian jembe drumming. Front. Neurosci. 10:285. doi: 10.3389/fnins.2016.00285

Pressing, J. (2002). Black atlantic rhythm: its computational and transcultural foundations. Music Percept. 19, 285-310. doi: 10.1525/mp.2002.19.3.285

Repp, B. H., and Su, Y.-H. (2013). Sensorimotor synchronization: a review of recent research (2006-2012). Psychonom. Bull. Rev. 20, 403-452. doi: $10.3758 / \mathrm{s} 13423-012-0371-2$

Ringli, D. (2006). Schweizer Volksmusik: Von den Anfängen um 1800 bis zur Gegenwart. Altdorf: Mühlirad.

Roholt, T. C. (2014). Groove: A Phenomenology of Rhythmic Nuance. New York, NY: Bloomsbury Publishing USA.

Ross, J. M., Warlaumont, A. S., Abney, D. H., Rigoli, L. M., and Balasubramaniam, R. (2016). Influence of musical groove on postural sway. J. Exp. Psychol. 42, 308-319 doi: $10.1037 / \mathrm{xhp} 0000198$

Sebanz, N., and Knoblich, G. (2010). "Embodied perception," in Encyclopedia of Perception, ed E. B. Goldstein (Thousand Oaks, CA: SAGE Publications, Inc), 388-390.

Senn, O., Bechtold, T. A., Hoesl, F., and Kilchenmann, L. (2019). Taste and familiarity affect the experience of groove in popular music. Music. Sci. 1-22. doi: $10.1177 / 1029864919839172$

Senn, O., Kilchenmann, L., Bechtold, T., and Hoesl, F. (2018). Groove in drum patterns as a function of both rhythmic properties and listeners' attitudes. PLoS ONE 13:e0199604. doi: 10.1371/journal.pone.0199604

Senn, O., Kilchenmann, L., von Georgi, R., and Bullerjahn, C. (2016). The effect of expert performance microtiming on listeners' experience of groove in swing or funk music. Front. Psychol. 7, 1-16. doi: 10.3389/fpsyg.2016.01487
Shaulov, N., and Lufi, D. (2009). Music and light during indoor cycling. Percept. Mot. Skills 108, 597-607. doi: 10.2466/pms.108.2.597-607

Sioros, G., Miron, M., Davies, M., Gouyon, F., and Madison, G. (2014). Syncopation creates the sensation of groove in synthesized music examples. Front. Psychol. 5:1036. doi: 10.3389/fpsyg.2014.01036

Sowinski, J., and Dalla Bella, S. (2013). Poor synchronization to the beat may result from deficient auditory-motor mapping. Neuropsychologia 51, 1952-1963. doi: 10.1016/j.neuropsychologia.2013.06.027

Spence, C., and Driver, J. (2004). Crossmodal Space and Crossmodal Attention. Oxford: Oxford University Press. doi: 10.1093/acprof:oso/9780198524861.001.0001

Steele, C. M., and Southwick, L. (1985). Alcohol and social behavior: I. The psychology of drunken excess. J. Pers. Soc. Psychol. 48, 18-34. doi: 10.1037/0022-3514.48.1.18

Swarbrick, D., Bosnyak, D., Livingstone, S. R., Bansal, J., Marsh-Rollo, S., Woolhouse, M. H., et al. (2019). How live music moves us: head movement differences in audiences to live versus recorded music. Front. Psychol. 9:2682. doi: $10.3389 /$ fpsyg.2018.02682

Thaut, M., and Hoemberg, V. (2014). Handbook of Neurologic Music Therapy. Oxford: Oxford University Press.

Thompson, S. (2007). Determinants of listeners' enjoyment of a performance. Psychol. Music 35, 20-36. doi: 10.1177/0305735607068886

Todd, N. P. M., and Cody, F. W. (2000). Vestibular responses to loud dance music: a physiological basis of the "rock and roll threshold"? J. Acoust. Soc. Am. 107, 496-500. doi: 10.1121/1.428317

Vurkaç, M. (2012). "Balanço: the contour of relative offbeatness," in Proceedings of BRIDGES: Mathematics, Music, Art, Architecture, Culture, (Towson: Towson University), 329-336.

Vuust, P., Dietz, M. J., Witek, M., and Kringelbach, M. L. (2018). Now you hear it: a predictive coding model for understanding rhythmic incongruity. Ann. N. Y. Acad. Sci. 1423, 19-29. doi: 10.1111/nyas.13622

Wesolowski, B. C., and Hofmann, A. (2016). There's more to groove than bass in electronic dance music: why some people won't dance to techno. PLoS ONE 11:e0163938. doi: 10.1371/journal.pone.0163938

Wilson, M. (2002). Six views of embodied cognition. Psychonom. Bull. Rev. 9 , 625-636. doi: 10.3758/BF03196322

Witek, M. A. G., Clarke, E. F., Wallentin, M., Kringelbach, M. L., and Vuust, P. (2014). Syncopation, body-movement and pleasure in groove music. PLoS ONE 9:e94446. doi: 10.1371/journal.pone.0094446

Wong, A. L., Haith, A. M., and Krakauer, J. W. (2015). Motor planning. Neuroscientist 21, 385-398. doi: 10.1177/10738584145 41484

Zatorre, R. J., Chen, J. L., and Penhune, V. B. (2007). When the brain plays music: auditory-motor interactions in music perception and production. Nat. Rev. Neurosci. 8, 547-558. doi: 10.1038/nrn2152

Zatorre, R. J., and Salimpoor, V. N. (2013). From perception to pleasure: Music and its neural substrates. Proc. Natl. Acad. Sci. 110(Suppl. 2), 10430-10437. doi: $10.1073 /$ pnas. 1301228110

Zbikowski, L. M. (2004). Modelling the groove: conceptual structure and popular music. J. R. Music. Assoc. 129, 272-297. doi: 10.1093/jrma/129.2.272

Conflict of Interest Statement: The authors declare that the research was conducted in the absence of any commercial or financial relationships that could be construed as a potential conflict of interest.

Copyright ( 2019 Senn, Rose, Bechtold, Kilchenmann, Hoesl, Jerjen, Baldassarre and Alessandri. This is an open-access article distributed under the terms of the Creative Commons Attribution License (CC BY). The use, distribution or reproduction in other forums is permitted, provided the original author(s) and the copyright owner(s) are credited and that the original publication in this journal is cited, in accordance with accepted academic practice. No use, distribution or reproduction is permitted which does not comply with these terms. 